\title{
Desain dan Pengembangan Fluxgate Magnetometer dan Beberapa Aplikasinya
}

\author{
Suyatno* \\ Jurusan Fisika FMIPA, Institut Teknologi Sepuluh Nopember \\ Kampus ITS Sukolilo, Surabaya 61111 \\ Mitra Djamal \\ Jurusan Fisika FMIPA, Institut Teknologi Bandung \\ Jl. Ganesha No.10, Bandung 40132 \\ Yulkifli \\ Jurusan Fisika, Universitas Negeri Padang, Padang \\ Rahmondia N.S \\ Program Pasca Sarjana Fisika, Institut Teknologi Bandung \\ Jl. Ganesha No.10, Bandung 40132
}

\section{Intisari}

\begin{abstract}
Telah dilakukan pembuatan dan pengembangan sensor magnetic fluxgate yang terdiri dari dua buah probe, berupa kumparan eksitasi, kumparan sekunder (pick-up) dan inti terbuat dari bahan vitrovac. Dengan menggunakan metode harmonisa kedua, penggunaan sensor ini adalah untuk mengukur besarnya medan magnetik, pengukuran arus pada penghantar dan pengukuran jarak. Pada pengukuran medan magnet didapatkan nilai pengukuran B hingga $20 \mathrm{nT}$ dengan sensitifitas $533,94 \mathrm{mV} / \mu \mathrm{T}$, dengan kesalahan absolut $200 \mathrm{mV}$ dan kesalahan relatif $2,76 \%$, sedang untuk pengukuran jarak, sensor ini mampu melakukan pengukuran jarak sampai pada jarak 13,8 mm dengan resolusi sampai pada $10 \mu \mathrm{m}$ dan kesalahan absolut $0,16 \mathrm{~mm}$ serta kesalahan relatif sebesar $3,4 \%$.
\end{abstract}

KATA KUNCI: sensor magnetik, Fluxgate Magneto Meter (FGM), harmonisa kedua

\section{PENDAHULUAN}

Penggunaan alat ukur dengan kemampuan pengukuran yang akurat, resolusi tinggi dan kemudahan serta keamanan dalam pemakaiannya sangatlah penting. Kunci dari semua itu terletak pada sensor yang digunakan untuk mengidentifikasi. Pengukuran medan magnet lemah sangat diperlukan dalam berbagai bidang, seperti: geofisika, geologi, kedokteran, oseanografi, dan ekspedisi luar angkasa. Pemetaan medan magnet merupakan hasil dari penggambaran medan magnet dalam ruang. Peta medan magnet diperlukan dalam mendisain magnet dalam akselerator partikel, spektrometer (massa, $n u$ clear magnetic resonance, electron spin resonance), dan sistem pencitraan resonansi magnetik. Peta medan magnet juga digunakan dalam eksplorasi geologi dengan variasi dalam besar dan arah medan magnet bumi merupakan gambaran dari bawah permukaan bumi. Peta medan magnet ini dibuat dengan sensor yang sensitif terhadap medan magnet bumi .

\footnotetext{
*E-MAIL: kangyatno@physics.its.ac.id
}

\section{FLUXGATE MAGNETOMETER}

Keberadaan medan magnet di sekitar dapat bersifat menguntungkan manusia dan ada juga yang bersifat mengganggu, namun sering kali kita tidak menyadarinya. Pengukuran medan magnet lemah dapat dilakukan dengan menggunakan fluxgate magnetometer. Fluxgate magnetometer adalah sensor yang bekerja berdasarkan perubahan medan magnet luar.

Salah satu bentuk probe sensor dalam sensor fluxgate adalah berbentuk lurus [1], probe ini terdiri dari inti yang terbuat dari logam khusus, kumparan primer dan kumparan sekunder. Probe yang dirancang di sini adalah probe sensor yang terdiri dua buah inti. Pada masing-masing inti dililitkan excitation coil atau kumparan eksitasi dan pick-up coil atau kumparan sekunder, tampak seperti pada Gambar 1.

Kumparan eksitasi berfungsi sebagai pembangkit medan magnet referensi. Pada kumparan eksitasi, medan listrik dialirkan dan diubah menjadi medan magnet. Besarnya medan magnet yang timbul secara matematis dirumuskan pada Pers.(1):[2]

$$
B=\mu i n
$$

dengan $\mu$ adalah nilai permeabilitas bahan, $\mathrm{i}$ adalah arus yang mengalir, $\mathrm{n}$ adalah jumlah lilitan persatuan panjang. 


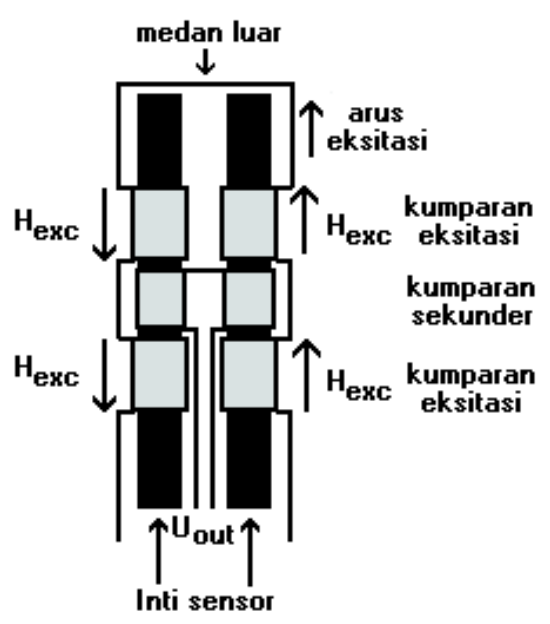

Gambar 1: Inti sensor fluxgate

Kumparan sekunder (pick-up coil) adalah kumparan yang berfungsi untuk mengubah besarnya perubahan medan magnet yang terjadi menjadi besaran listrik.

Besarnya tegangan yang terjadi secara matematika dirumuskan pada Pers.(2):[2]

$$
E=-N \frac{d \Phi}{d t}=-N \frac{d(B A)}{d t}
$$

Pada kumparan eksitasi, arus yang dialirkan dikendalikan oleh sebuah osilator frekuensi. Frekuensi osilator ditentukan oleh frekuensi dari kristal untuk fluxgate magnetometer yaitu 1-20 kHz [2], di sini digunakan osilator dengan frekuensi 4 $\mathrm{kHz}$, dengan frekuensi sebesar ini hasil yang diperoleh lebih optimal. Frekuensi yang digunakan untuk kumparan eksitasi adalah setengah dari frekuensi ini yaitu $2 \mathrm{kHz}$ (f), dan frekuensi $4 \mathrm{kHz}$ (2f) digunakan untuk detektor fasa.

Kumparan eksitasi dililitkan pada ujung masing-masing inti sensor, sedangkan kumparan sekunder dililitkan di tengah inti sensor. Ini dilakukan agar kumparan sekunder lebih sensitif terhadap flux medan magnet yang dilingkupinya, karena langsung melingkupi inti sensor. Dengan melilitkan kumparan eksitasi pada ujung-ujung inti, diharapkan inti akan mencapai saturasi, dan medan magnet di sepanjang inti akan homogen, ini juga didukung oleh daerah yang dilingkupi oleh kumparan eksitasi lebih panjang dari kumparan sekunder. Ketika kumparan eksitasi dialiri arus eksitasi bolak-balik, akibatnya akan timbul medan eksitasi yang berarah bolakbalik sesuai dengan arus yang mengendalikannya. Medan ini akan mensaturasikan inti yang mempunyai permeabilitas tertentu yang lebih besar dari permeabilitas udara. Ketika inti tersaturasi, medan magnet di sekitar inti akan homogen.

Demikian pula pada inti sensor yang kedua, kumparan eksitasi dililitkan pada ujung-ujung inti, dan kumparan sekunder di tengah, tapi keluaran kumparan sekunder dibuat saling berlawanan. Karena arah kumparan eksitasi dibuat searah untuk kedua inti dan agar tegangan keluaran dari kumparan sekunder berlawanan, maka arah lilitan kumparan sekunder



[a]

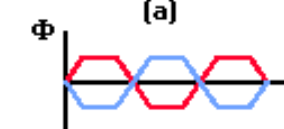

[c]

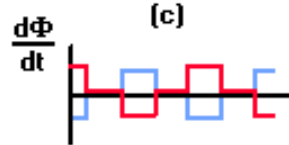

[e]

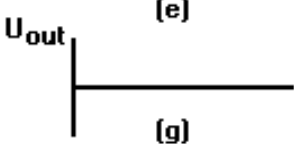

[g]

$H_{0}=0$



[b]

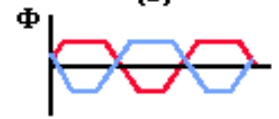

[d]



$\mathrm{H}_{\mathbf{0}} \mp 0$
Gambar 2: Cara kerja probe sensor

pada inti kedua dibuat berlawanan dengan lilitan pada inti pertama, jika arah lilitan pada inti pertama ke kanan, maka arah lilitan pada inti kedua ke kiri. Struktur inti sensor dapat dilihat pada Gambar 1.

Keluaran kumparan sekunder akan nol ketika di sekitar sensor tidak terdapat medan magnet, ini terjadi karena tegangan dari masing-masing kumparan sekunder sama tapi berlawanan tanda, dan jika dilihat dari Gambar 2.e, hal ini akan terlihat simetris, sehingga jika dijumlahkan hasilnya akan nol. Tapi jika terdapat medan magnet luar yang searah atau resultannya searah dengan inti sensor, maka inti akan lebih cepat tersaturasi dalam satu arah tertentu, maka tegangan antara kedua kumparan sekunder tidak akan sama lagi, karena medan luar akan bersifat kostruktif terhadap medan eksitasi yang searah dengannya, dan destruktif terhadap medan eksitasi yang berlawanan arah dengannya, ini akan menyebabkan ketaksimetrisan pada $\mathrm{H}$ dan $\Phi$, seperti pada Gambar 2.b dan Gambar 2.d, dan setelah didiferensialkan dan dijumlahkan (Gambar 2.f), maka terdapat pulsa-pulsa, jika medan magnet semakin kuat, lebar pulsa akan semakin membesar, pulsa-pulsa inilah yang menyebabkan keluaran ujung-ujung kumparan sekunder tidak nol.[3-5]

Tegangan keluaran kumparan sekunder ketika ada medan magnet luar ini sebanding dengan kuat medan yang berasal dari luar, dapat dikatakan bahwa tegangan keluaran ini merupakan representasi dari kuat medan magnet di sekitar sensor, sehingga tegangan keluaran sensor ini dapat digunakan untuk mengukur kuat medan magnet yang terdeteksi. Karena keluaran probe sensor ini masih berupa pulsa-pulsa, maka perlu diolah lebih lanjut.[6, 7]

\section{METODOLOGI}

Dalam tulisan ini dilakukan desain dan pengembangan fluxgate magnetometer yang digunakan sebagai sensor magnetik 


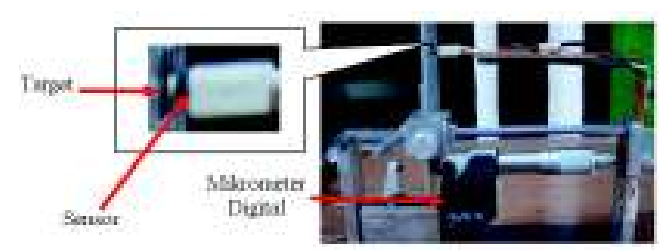

Gambar 3: Skema pengukuran jarak dengan menggunakan sensor fluxgate

untuk melakukan pengukuran:

1. medan magnet lemah pada pengujian respon sensor terhadap perubahan medan magnet luar, pengujian terhadap perubahan arus, dengan menggunakan kalibrator magnet dan arus

2. jarak pengukuran jarak dilakukan dengan menggunakan mikrometer digital sebagai pembanding.

Dari data dan analisis tersebut nantinya dapat ditarik kesimpulan hal ini terkait dengan performa dan kelebihan yang dimiliki oleh fluxgate magnetometer dibandingkan dengan yang lainnya. Skema pengukuran yang dilakukan tampak seperti Gambar 3.

\section{HASIL DAN DISKUSI}

Aplikasi FGM (Fluxgate Magnetometer) sebagai alat ukur didasarkan pada pengukuran medan magnet. Medan magnet yang terukur nantinya akan diproses oleh rangkaian pengolah sinyal kemudian ditampilkan dalam bentuk displai.

\section{A. Pengukuran medan magnet}

Pengukuran medan magnet dimaksudkan untuk mendeteksi besarnya pengaruh medan magnet di suatu tempat. Pengukuran dilakukan dengan meletakkan sensor pada suatu tempat, maka akan diketahui besarnya intensitas medan yang terjadi. Pengukuran ini dapat juga digunakan sebagai penunjuk arah (kompas elektronik).

Dalam tahap awal, pengukuran medan magnet dilakukan untuk mengetahui respon sensor terhadap sumber medan magnet. Pengukuran dilakukan dengan meletakkan sensor pada sebuah solenoida berarus yang besarnya arus listrik dapat kita kontrol, sehingga dapat diketahui besarnya medan magnet yang terjadi. Dari pengukuran yang telah dilakukan didapatkan data pengukuran seperti ditunjukkan Gambar 4.

Dari Gambar 4 tampak bahwa daerah linier terdapat pada daerah medan magnet antara $-20 \mathrm{~T}$ hingga $20 \mathrm{~T}$, pada daerah ini terdapat perbandingan yang lurus antara tagangan keluaran dengan medan magnetik yang diukur, dengan demikian magnetometer bekerja dengan baik pada daerah ini. Daerah kerja magnetometer ini tampak pada Gambar 5.



Gambar 4: Keluaran akhir sensor

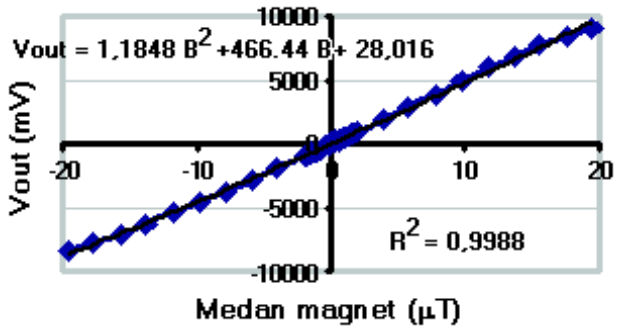

Gambar 5: Keluaran medan magnet pada daerah kerja

Untuk mengetahui kesalahan sensor, keluaran daerah kerja sensor ini dapat didekati dengan polinomial orde dua. Dapat dilihat dari gambar bahwa keluaran tersebut dapat didekati dengan Pers.(3) :

$$
V_{\text {out }}=1,1848 B^{2}+466,44 B+28,016
$$

dari persamaan di atas dapat diketahui sensitivitas sensor, karena koefisien $B^{2}$ sangat kecil dibandingkan koefisien B, maka untuk B yang kecil, sensitivitas sensor adalah koefisien B yaitu $466,44 \mathrm{mV} / \mu \mathrm{T}$.

\section{B. Pengukuran jarak.}

Pengukuran jarak dilakukan dengan meletakkan sebuah target dari bahan konduktor sebagai medan pengganggu. Sumber medan magnet yang dihasilkan oleh sensor akan mengenai target. Didalam target, medan magnet yang terjadi akan berubah menjadi listrik induksi (hukum Faraday). Akibat adanya arus induksi pada target, maka akan timbul magnet induksi di sekitarnya. Besarnya magnet induksi yang tejadi akan berpengaruh terhadap intensitas medan magnet yang diterima oleh pick-up coil. Perubahan intensitas yang terjadi sebanding dengan perubahan jarak antara target dengan sensor. Dari hasil pengukuran yang telah dilakukan didapatkan hasil seperti pada Gambar 6.

Dari Gambar 6 tampak bahwa perubahan jarak yang terjadi antara target dengan sensor akan berbanding terbalik dengan perubahan tegangan yang dihasilkan. Dengan persamaan pendekatannya adalah :

$$
y=-0,1045 x+2,8162
$$






Gambar 6: Grafik hasil kalibrasi Statis sensor

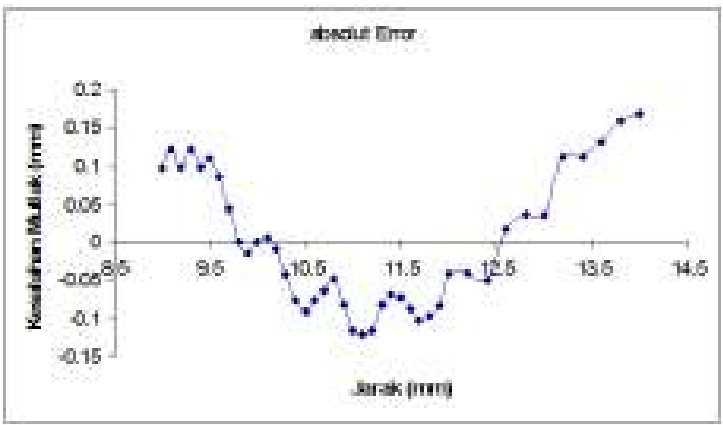

Gambar 7: Kesalahan absolut pengukuran

dengan y dalam volt dan $\mathrm{x}$ dalam $\mathrm{mm}$.

Hal ini berarti medan magnet yang diterima oleh sensor akan sebanding dengan jarak yang terjadi, karena perubahan medan magnet akan menyebabkan perubahan tegangan keluaran sensor (Pers.(4)). Dari data yang didapatkan dapat diketahui besarnya kesalahan absout pengukuran dan kesalahan relatifnya, seperti tampak pada Gambar 7.
Pada Gambar 7 dan Gambar 8 menunjukkan bahwa kesalahan absolut pengukuran yang terjadi adalah $0,16 \mathrm{~mm}$ dan kesalahan relatifnya adalah $3,4 \%$.



Gambar 8: Kesalahan relatif pengukuran

V. SIMPULAN

Dari penelitian yang telah dilakukan, dapat diambil kesimpulan antara lain adalah:

1. Fluxgate magnetometer adalah sensor yang mampu melakukan pengukuran dengan metode non-kontak.

2. Untuk pengukuran medan magnet, Fluxgate magnetometer mampu melakukan pengukuran medan magnet sampai pada $20 \mathrm{nT}$ dengan sensitifitas $533,94 \mathrm{mV} / \mu \mathrm{T}$

3. Fluxgate magnetometer mampu digunakan sebagai sensor jarak antara target (bahan konduktor) dengan sensor pada jarak sampai $12.68 \mathrm{~mm}$ dengan resolusi $10 \mathrm{~mm}$ dan kesalahan absolute $0,16 \mathrm{~mm}$ serta kesalahan relative adalah $3,4 \%$.
[1] Bish. A., B.J. Fraser dkk., Magnetik Field Measurements in Space: The New Mag Magnetometer, (Department of Physics, University of Newcastle, Callaghan, 2000)

[2] http:/hyperphysics.phy-astr.gsu.edu/hbase/magnetic/ solenoid.html\#c2

[3] Fraden, J., Handbook of Modern Sensor: physics, design, and application, 2nd edition, (Springer-Verlag, New York, 1996)

[4] Gopel, W., Sensor a Comprehensive Survey Volume 5 Magnetik Sensor (VCH, Weinhein, 1989)

[5] Rahmondia N. S, Perancangan dan Pembuatan sensor Medan Magnet Fluxgate dengan Metoda Posisi Pulsa, Tugas akhir 2, Fisika ITB, 2004.

[6] Grger, H., Gottfried-Gottfried, R., CMOS Integrated Two Axes Magnetik Field Sensors - Miniaturized Low Cost Systems With Large Temperature Range (Fraunhofer Institute for Microelec- tronic Circuits and Systems IMS, Dresden, 2000)

[7] http://www.sensorsmag.com/articles/1298/mag1298/main.shtml

[8] Sutrisno, Elektronika Teori dan Penerapannya Jilid 1 (Penerbit ITB, Bandung, 1986)

[9] Sutrisno, Elektronika Teori dan Penerapannya Jilid 2 (Penerbit ITB, Bandung, 1986)

[10] Wildian, Sistem Pengukuran Arus DC Berbasis GMR, Thesis Magister, Departemen Fisika, ITB, Bandung, 2002

[11] Piil-Henriksen, P., G Merayo. JM., dkk., Meas. Sci. Technol. 7 897-903., UK (1996)

[12] http://maxwell.byu.edu/ spencerr/websumm12.2/node70.html

[13] P. Malvino, Electronic Principles 6th ed. (The McGraw-Hill Book Companies, Inc., 1999) 